\title{
Organização de acervo fotográfico histórico: proposta de descrição
}

\author{
Organization of historical photographic collection: proposal description
}

Renata Cardozo Padilha

Mestre em Ciência da Informação pela Universidade Federal de Santa Catarina - UFSC.

Email: renatapadilha@hotmail.com

Lígia Maria Arruda Café

Doutora em Lingüística pela Université Laval, Canadá.

Professora Programa de Pós-Graduação em Ciência da Informação da Universidade Federal de Santa Catarina -

UFSC

Email: ligia.cafe@ufsc.br

\begin{abstract}
Resumo
Reflexão a respeito da construção de uma proposta de descrição para fotografias históricas salvaguardadas em acervo de museus, por meio de um conjunto de metadados que atenda as necessidades informacionais do pesquisador. Apresenta questões relacionadas com o museu, a documentação museológica, a organização da informação, metadados e descrição de acervos fotográficos históricos para conceituar a proposta. Como metodologia, elaborou-se, com base em dois modelos, uma ficha documental para servir de ferramenta na inserção dos metadados. Por meio da análise das fichas de catalogação de acervos fotográficos históricos dos Museus de Imagem e Som do sul e sudeste do Brasil e de consulta à bibliografia especializada, constituiu-se o conjunto de metadados para descrição de fotografia histórica. Espera-se com a criação da proposta contribuir para que os museus venham ocupar cada vez mais seu papel como entidades de pesquisa, por meio da organização do seu acervo e da valorização dos objetos enquanto fonte de informação. Conclui-se que a fotografia histórica salvaguardada pelos museus é uma fonte de informação para a pesquisa científica e que para tanto deve ser descrita de forma que atenda o previsto pelo sistema de documentação museológica que visa identificar às características informacionais intrínsecas e extrínsecas do objeto.
\end{abstract}

Palavras-chave: Acervo fotográfico histórico. Museu. Documentação museológica. Organização da informação. Metadados.

\begin{abstract}
Reflection about the construction of a proposed description for historical photographs safeguarded in museums' collections, through a set of metadata that meets the informational needs of the researcher. Presents issues related to the museum, the museological documentation, information organization, metadata and description of historical photographic collections to conceptualize the proposal. As methodology, was elaborated, on the basis of two models, a documentary record to be used as a instrument for the metadata insertion. Through the analysis of documentary records of historical photographic collections of the Museum of Image and Sound in the south and southeast of Brazil and consulting the relevant literature, the set of metadata for describing historical photograph was formulated. It is hoped that the creation of the proposal contributes for the museums take on increasingly his role as research entities, through the organization of the collections and appreciation of objects as a source of information. It is concluded that the historical photograph safeguarded by museums is a source of information for scientific research and therefore should be described in way that addresses the museological documentation premises, that aims to identify the intrinsic and extrinsic informational characteristics of the object.
\end{abstract}

Keywords: Historical photographic collection. Museum. Museological documentation. Information Organization. Metadata.

InCID: R. Ci. Inf. e Doc., Ribeirão Preto, v. 5, n. 1, p. 90-111, mar./ago. 2014.

DOI: 10.11606/issn.2178-2075.v5i1p90-111 


\section{Introdução}

O presente artigo visa apresentar uma reflexão a respeito da construção de uma proposta de descrição para fotografias históricas salvaguardadas em acervo de museus, elaborada como resultado da dissertação de mestrado da autora ${ }^{1}$ intitulada "O museu como espaço de pesquisa: proposta para descrição do acervo fotográfico". Essa pesquisa teve como base a proposta de uma organização que atendesse às necessidades de informação do pesquisador cujo objeto de pesquisa é a fotografia histórica. Sendo assim elaboramos um conjunto de metadados para a descrição deste acervo de modo que o sistema de documentação museológica fosse contemplado.

Evidenciamos dentre as diversas práticas desenvolvidas no museu, tendo em vista sua função social e cultural, o papel que esse carrega consigo enquanto espaço destinado à pesquisa e que incentiva a produção de conhecimento por intermédio de seu acervo. Nesse contexto, identificam-se os objetos preservados no museu como fontes de informação/documento e que, para se configurarem como tal, necessitam estar organizados e sistematizados de modo a atender não só os funcionários do museu e o público em geral, como também, o pesquisador especializado que visa obter informações detalhadas sobre seu objeto de estudo.

O objeto, ao ser adquirido pelo museu, passa por uma ressignificação de sentidos e funções, ou seja, se torna um objeto musealizado, o qual deve ser evidenciado suas características intrínsecas e extrínsecas (FERREZ, 1994) a ele, e que para tanto necessita ser documentado nas múltiplas possibilidades informacionais que o envolvem. Neste contexto, a trajetória do objeto passa a ser relatada sob duas circunstâncias: sua vida útil antes de fazer parte do museu e depois, quando ganha novos usos dentro deste espaço. Ao pensar no objeto museológico, identificamos que este pode ser bi ou tridimensional, de ampla variedade tipológica, podendo ser de cunho etnográfico, arqueológico, artístico, de ciências naturais, tecnológico, imagético, sonoro, digital, entre outros.

Optamos pela escolha dos objetos imagéticos, especificamente a fotografia histórica, tendo em vista que, além de ser apreciada por meio de seu valor patrimonial, é também fonte de pesquisa científica (LOIZOS, 2008) e/ou fonte documental histórica (KOSSOY, 2001). Consideramos fotografia histórica como "toda aquela que nos chega às mãos pronta, tendo

\footnotetext{
${ }^{1}$ Renata Padilha sob orientação da Profa. Dra. Lígia Café, pelo Programa de Pós-Graduação em Ciência da Informação da Universidade Federal de Santa Catarina.
}

InCID: R. Ci. Inf. e Doc., Ribeirão Preto, v. 5, n. 1, p. 90-111, mar./ago. 2014. 
sido produzida há algum tempo, com relação ao momento em que é analisada pelo observador." (LEITE, 2001, p.15). Trata-se, portanto, daquela que, por meio do seu suporte físico e de seu conteúdo imagético, possa ser investigada no que diz respeito ao seu contexto histórico, social, cultural, econômico e artístico no qual foi produzida dentro de um espaçotempo (KOSSOY, 2001) determinado. Neste caso, estabelecemos o período que corresponde, aproximadamente, dos meados do século XIX ao final do século XX.

Tendo por base a relação da Ciência da Informação com a Museologia (BARBUY, 2008), a construção de nossa proposta baseia-se em olhar a instituição museu pela perspectiva da Organização da Informação, tendo em vista que essa pode preencher lacunas ainda sem solução no funcionamento dos sistemas de informação e documentação dos museus.

\section{Museu e documentação}

As instituições museológicas com o passar dos anos começam a se reformular, e a preocupação com a organização e disseminação da informação passa ser necessária. Os objetos ao entrarem nos museus são ordenados, classificados, interpretados, analisados e divulgados de modo que o público possa construir conhecimento. Conforme o Estatuto Brasileiro de Museus, Lei $n^{\circ} 11.904 / 2009$ (Art. $1^{\circ}$ ), é considerado museu as

\footnotetext{
instituições sem fins lucrativos que conservam, investigam, comunicam, interpretam e expõem, para fins de preservação, estudo, pesquisa, educação, contemplação e turismo, conjuntos e coleções de valor histórico, artístico, científico, técnico ou de qualquer outra natureza cultural, aberta ao público a serviço da sociedade e de seu desenvolvimento (BRASIL, 2009, grifo nosso).
}

Nesse contexto, enfatizamos a finalidade de pesquisa, determinado em lei, para abordarmos as questões referentes a esta função que os museus devem desenvolver em suas práticas institucionais, tanto para a realização das suas atividades como também para tornar acessível seu acervo ao público. Segundo Vinos Sofka (2009, p. 84), um dos criadores do International Committee for Museology - ICOFOM, a que se reconhecer a importância da pesquisa científica nos museus e sobre os museus, pois "a pesquisa científica nos museus é uma das tarefas primordiais, uma necessidade óbvia. É tão óbvia que já não pode ser restrita apenas às coleções de um museu específico. Mas, para os museus e a sua organização [...]”.

Ao pensar nessa pesquisa que o museu deve proporcionar para seu público/pesquisador, Ferrez (1994, p.65) expõe que:

InCID: R. Ci. Inf. e Doc., Ribeirão Preto, v. 5, n. 1, p. 90-111, mar./ago. 2014. 
[...] os museus a partir das suas funções, constata-se que são instituições estreitamente ligadas à informação de que são portadores os objetos e espécimes de suas coleções. Estes, como veículo de informação, têm na conservação e na documentação as bases para se transforma em fontes para a pesquisa científica e para a comunicação que, por sua vez, geram e disseminam novas informações.

Os motivos que levam os museus salvaguardarem os objetos são inúmeros, porém é inegável que qualquer uma dessas razões está atrelada as potencialidades de informação dos objetos, basta questioná-los para que comecem a surgir possibilidades de respostas sobre seus usos, materiais, relações sociais, entre outros. De tal maneira, consideramos imprescindível que as etapas de desenvolvimento das coleções sejam cumpridas ordenadamente, da entrada do objeto no museu a disseminação da informação, para que assim os passos que correspondem à tríade preservação, pesquisa e comunicação sejam possíveis. Nesse caso, destacamos a documentação como procedimento que perpassa todos os caminhos do museu, pois de acordo com Loureiro (2008, p.27-28) “[...] a documentação organiza domínios de informação instituindo processos e construindo instrumentos essenciais nos quais os diversos produtores e usuários de informação possam estabelecer princípios racionais de preservação, gestão e acesso a informação".

Smit (2011, p. 35) apresenta um quadro em que exibe os diferentes tipos de documentos presentes no museu, sendo eles: objetos, documento de gestão do acervo museológico, documento gerado pelo uso do acervo museológico, documento de apoio, documentos administrativos. A análise deste quadro nos permite verificar as atividades que contemplam a documentação dos acervos visando o tratamento sistemático do conjunto de dados informacionais contidos em cada um dos objetos pertencentes às coleções do museu, bem como de todas as práticas desenvolvidas na instituição. Smit (2011, p.38) ainda traz para essa discussão a necessidade de nos atentarmos "para dois conjuntos de usuários: as pessoas vinculadas ao museu (conservadores, museólogos, curadores etc.) e os usuários não vinculados formalmente ao museu, ou seja, o "público"”.

Os objetos no percurso de sua existência perdem e ganham informações em consequência de sua funcionalidade, consertos e deterioração. Quando adentra a instituição museológica, o objeto inicia uma nova história que deverá continuar sendo documentada (FERREZ, 1994). O intuito desse sistema é conservar os objetos da coleção, potencializar o acesso e elevar ao máximo o uso da informação contida neles. São componentes desse processo: a entrada que tange a seleção e aquisição; a organização e controle que compete o registro, número de identificação/marcação, armazenagem/localização, 
classificação/catalogação e indexação; e as saídas que são as etapas de recuperação e disseminação da informação (FERREZ, 1994).

A documentação precisa dar conta dessas informações, para que os museus não corram o risco de se tornarem depósitos de objetos sem sentido e passado, por isso a clareza e exatidão dos dados, a definição dos campos de informação, normalização de procedimentos, controle terminológico, segurança da documentação, entre outros, devem ser atentamente desenvolvidos.

\section{Organização da informação para acervo fotográfico histórico}

Conforme expõe Bräscher e Café (2008, p. 5), “o objetivo do processo de organização da informação é possibilitar o acesso ao conhecimento contido na informação". Para tanto, é necessário realizar a descrição física e de conteúdo dos objetos informacionais, o que resulta na representação da informação. Conforme Café e Sales (2010, p. 118), “a descrição física de um objeto informacional se dá pelo processo de catalogação cujo resultado é a representação do suporte físico ou documento. Pode utilizar linguagem específica, normas e formatos que padronizam esse tipo de descrição".

O processo de descrição do conteúdo leva o nome de análise documentária, esta conceituada, segundo Cunha (1987, p. 40), “como um conjunto de procedimentos efetuados com o fim de expressar o conteúdo de documentos, sob formas destinadas a facilitar a recuperação da informação". É importante destacar que na análise documentária três elementos estão presentes: a linguagem do documento, do sistema e do usuário. Essa questão leva as unidades de informação a adotarem esquemas que padronizem a descrição da informação, visando respeitar a terminologia do usuário/público/pesquisador. Estes esquemas são denominados de linguagens documentárias que, de acordo com Cintra (2002, p. 33), "são construídas para indexação, armazenamento e recuperação da informação e correspondem a sistemas de símbolos destinados a 'traduzir' os conteúdos dos documentos." para a linguagem do sistema de recuperação da informação. Ortega (2008, p.2) denomina o produto da organização da informação como informação documentária e a define como:

[...] unidades de representação, construídas sob uma forma e um conteúdo, a partir de decisões pautadas nos tipos de informação nas áreas do conhecimento ou de atividade, na linguagem dos usuários e nos objetivos do serviço de informação, tornando explícito o propósito de um sistema de informação.

InCID: R. Ci. Inf. e Doc., Ribeirão Preto, v. 5, n. 1, p. 90-111, mar./ago. 2014. 
$\mathrm{Na}$ atualidade, a informação documentária pode ser registrada em metadados, que, segundo Campos, Campos e Campos (2006, p. 60), têm por finalidade principal "documentar, com elementos descritores, qualquer tipo de recurso disponível na Web, para permitir comunicabilidade e interoperabilidade entre sistemas.". Entende-se que metadados são dados sobre dados, ou seja, "são dados associados a um recurso web, um documento eletrônico, por exemplo, que permitem recuperá-lo, descrevê-lo e avaliar sua relevância, manipulá-lo [...], gerenciá-lo, utilizá-lo [...]” (MARCONDES, 2006, p. 97).

Tendo em vista que os museus são detentores de diversos tipos de acervos, entre os quais se destaca o acervo fotográfico histórico, evidenciamos a fotografia, como objeto informacional que possui especificidades cuja descrição requer metodologia de análise própria que a caracterize como informação (SMIT, 1996). Neste contexto duas obras foram consideradas fundamentais para a descrição de fotografias: Manini (2008) e Kossoy (2001).

A primeira delas foi eleita diante das reflexões acerca da precisão com relação ao conteúdo informacional e da técnica que devem ser consideradas no tratamento documental da fotografia. Não faz distinção quanto ao tipo de unidade de informação (arquivos, bibliotecas, centros de documentação e museus) que a preserva, mesmo destacando que este objeto pode dispor de diversas informações, dependendo do contexto em que se insere. Seu estudo enfatiza a fotografia como um artefato passível de representação e que por isso necessita de tratamento adequado para que haja uma recuperação eficiente da sua informação nestes espaços. Manini (2008), por meio de um quadro proposto com base na teoria de Smit (1997), apresenta um conjunto referencial de meta-características da imagem fotográfica, não fazendo distinção quanto à fotografia histórica e fotografia artística ${ }^{2}$, mas voltado ao processo de descrição proveniente de estudos na área da Ciência da Informação. O quadro 1 a seguir mostra o quadro proposto por Manini (2008).

\footnotetext{
${ }^{2}$ Consideramos esta como "arte-fotografia" conforme apresenta Rouillé (2009), na qual trata as fotomontagens como criações imagéticas que associam duas ou mais imagens, ou fragmento de imagens com a finalidade de gerar uma nova imagem.
} 
Quadro 1: Proposta de Manini (2008) para análise de fotografia

\begin{tabular}{|l|l|l|l|l|}
\hline \multirow{4}{*}{} & \multicolumn{3}{l|}{ Conteúdo Informacional } & Dimensão \\
\cline { 2 - 5 } & \multicolumn{2}{|l|}{ DE } & SOBRE & Expressiva \\
\hline Categoria & Genérico & Específico & & \\
\hline Quem/O que & & & & \\
\hline Onde & & & & \\
\hline Quando & & & & \\
\hline Como & & & & \\
\hline
\end{tabular}

Fonte: Quadro elaborado por Manini (2008) com base na grade de Smit (1997).

Por outro lado, verificamos que como cada unidade de informação possui métodos e técnicas distintas de concepção institucional, somente a proposta de Manini (2008) não traria densidade ao trabalho, uma vez que estamos abordando o acervo fotográfico histórico inserido no espaço museológico, e que, para tanto, exige outras formas de descrição voltadas especificamente para a recuperação em museus por pesquisadores.

A escolha pela obra de Kossoy (2001) se justifica tendo em vista a sua preocupação em compreender a fotografia histórica como um objeto de museu que possui informações referentes tanto ao seu conteúdo imagético como seu contexto externo, que diz respeito tanto ao suporte físico quanto as relações históricas que o compõem. O historiador, ao expor um roteiro contendo os itens considerados relevantes no que tange a fotografia histórica como fonte de pesquisa histórica, evidencia que são igualmente importantes as questões relacionadas ao suporte físico, o conteúdo informacional e as relações externas ao objeto. Para tanto, ilustramos no quadro 2 o que em cada item do roteiro proposto ele recomenda conter para a descrição da fotografia, objeto de museu, também, considerada como fonte histórica. 
Quadro 2: Roteiro de Kossoy (2001) para pesquisa e análise de fotografias

\begin{tabular}{|c|c|c|c|}
\hline $\begin{array}{l}\text { 1. Identidade do documento + } \\
\text { características individuais }\end{array}$ & $\begin{array}{l}\text { 2. Informações referentes ao } \\
\text { assunto (tema representado na } \\
\text { imagem) }\end{array}$ & $\begin{array}{l}\text { 3. Informações referentes ao } \\
\text { fotógrafo (autor do registro) }\end{array}$ & $\begin{array}{l}\text { 4. Informações referentes à } \\
\text { tecnologia }\end{array}$ \\
\hline № de registro/ Título & Referência visual do documento & $\begin{array}{l}\text { Fotógrafo ou estabelecimento (autor do } \\
\text { registro) }\end{array}$ & $\begin{array}{c}\text { Quando se trata de um original fotográfico } \\
\text { de época: equipamento utilizado, natureza } \\
\text { do original, suporte da superfície, } \\
\text { fotossensível, processo fotográfico } \\
\text { empregado, textura da superfície do papel } \\
\text { fotográfico, tonalidade, formato da } \\
\text { imagem (dimensão), característica da } \\
\text { montagem. }\end{array}$ \\
\hline Localização do documento na inst. & $\begin{array}{l}\text { Descritores de conteúdo (palavras-chave } \\
\text { - inventário temático/ relacionado ao } \\
\text { conteúdo) }\end{array}$ & $\begin{array}{c}\text { Autoria por atribuição: tipo de montagem, } \\
\text { cenários de estúdio no caso de retratos, } \\
\text { caract. De estilo, fotógrafos atuantes no } \\
\text { local na época em que a fotografia foi } \\
\text { produzida. }\end{array}$ & \\
\hline $\begin{array}{l}\text { Procedência: origem da aquisição, tipo de } \\
\text { aquisição, data, especificar número do } \\
\text { processo (se for inst. Pública), foi } \\
\text { adquirido com outros documentos?, é } \\
\text { peça avulsa ou faz parte de um conj. de } \\
\text { fotos?, recuperar dados bibliográficos se } \\
\text { faz parte de álbum ou publicação. }\end{array}$ & Anotações no documento matriz & $\begin{array}{l}\text { Pistas que levem à determinação de } \\
\text { contratante do serviço fotográfico }\end{array}$ & \\
\hline $\begin{array}{l}\text { Conservação: estado atual, condições } \\
\text { físicas que se acha armazenado, } \\
\text { condições ambientais que se acha } \\
\text { armazenado. }\end{array}$ & Descrição concisa do tema & & \\
\hline
\end{tabular}

Fonte: criado pela autora com base na obra de Kossoy, 2001, 2013

\section{Metodologia}

Para a realização da proposta de descrição de fotografia histórica salvaguardada em museus, foram adotados três critérios:

1. Seleção dos autores Manini (2008) e Kossoy (2001) para a elaboração da ficha documental que serviu de ferramenta para inserção dos metadados.

2. Análise das fichas de catalogação de acervos fotográficos históricos dos Museus de Imagem e do Som situados no sul e sudeste do Brasil, sendo esses: Fundação Museu da Imagem e do Som do Rio de Janeiro (RJ), Museu da Imagem e do Som de São Paulo (SP), Museu da Imagem e do Som do Paraná (PR) e Museu da Imagem e do Som de Santa Catarina (SC).

3. Interpretação da bibliografia especializada sobre fotografia, história da fotografia, análise de conteúdo de imagens fotográficas, fotografia como documento de pesquisa, 
objeto museológico, documentação museológica, fichas de catalogação de fotografia histórica de museus estrangeiros ${ }^{3}$, entre outros.

Ao constatar que ambos os estudiosos Manini (2008) e Kossoy (2001), pensam por vias distintas a organização e representação de fotografias, destacamos a importância de unir essas duas referências para construir uma nova forma de pensar o acervo fotográfico histórico inserido no contexto do espaço museológico. Identificamos que cada autor possui peculiaridades extremamente relevantes no que tange às formas de refletir a organização e representação da fotografia, fato que se justifica em função de suas áreas de origem. Manini (2008), pelo viés da Ciência da Informação, constrói a grade de análise (quadro 1) para descrição de qualquer tipo de fotografia independente se está é histórica ou artística. O historiador Kossoy (2001), por outro lado, pensa especificamente a fotografia histórica, propondo várias facetas de análise (quadro 2) deste tipo de documento, agregando características informacionais intrínsecas e extrínsecas (FERREZ, 1994) a ele.

Neste contexto, observamos a obra de Manini (2008) sob a luz do roteiro de Kossoy (2001), estudo que resultou na ficha documental abaixo (quadro 3). Estabelecemos esta ferramenta de análise específica que busca a compreensão dos metadados que descrevem as fotografias históricas, no que tange às características informacionais intrínsecas e extrínsecas do objeto museológico.

Quadro 3: Ficha Documental

\begin{tabular}{|c|c|c|c|c|c|c|c|}
\hline \multicolumn{2}{|c|}{$\begin{array}{l}\text { 1. Identidade do documento + } \\
\text { características individuais }\end{array}$} & \multicolumn{2}{|c|}{$\begin{array}{l}\text { 2. Informações referentes ao } \\
\text { assunto }\end{array}$} & \multicolumn{2}{|c|}{$\begin{array}{l}\text { 3. Informações referentes ao } \\
\text { fotógrafo }\end{array}$} & \multicolumn{2}{|c|}{$\begin{array}{l}\text { 4. Informações referentes à } \\
\text { tecnologia }\end{array}$} \\
\hline \multicolumn{2}{|c|}{$\mathrm{DE}$} & \multicolumn{2}{|c|}{$\mathrm{DE}$} & \multicolumn{2}{|c|}{$\mathrm{DE}$} & \multicolumn{2}{|c|}{$\mathrm{DE}$} \\
\hline Genérico & Especifico & Genérico & Especifico & Genérico & Especifico & Genérico & Especifico \\
\hline Quem/o que & Quem/o que & Quem/o que & Quem/o que & Quem/o que & Quem/o que & Quem/o que & Quem/o que \\
\hline Onde & Onde & Onde & Onde & Onde & Onde & Onde & Onde \\
\hline Quando & Quando & Quando & Quando & Quando & Quando & Quando & Quando \\
\hline Como & Como & Como & Como & Como & Como & Como & Como \\
\hline \multicolumn{2}{|l|}{ Sobre } & \multicolumn{2}{|l|}{ Sobre } & \multicolumn{2}{|l|}{ Sobre } & \multicolumn{2}{|l|}{ Sobre } \\
\hline \multicolumn{2}{|c|}{ Dimensão expressiva } & \multicolumn{2}{|c|}{ Dimensão expressiva } & \multicolumn{2}{|c|}{ Dimensão expressiva } & \multicolumn{2}{|c|}{ Dimensão expressiva } \\
\hline
\end{tabular}

Fonte: criado pela autora com base nas obras de Kossoy (2001) e Manini (2008), 2013.

\footnotetext{
${ }^{3}$ Utilizamos como exemplo as bases MatrizNet Portugal, Joconde Portail des Coections des musées de France, Getty Research Institute Digital para justificar as escolhas feitas de alguns metadados, servindo como reforço argumentativo
}

InCID: R. Ci. Inf. e Doc., Ribeirão Preto, v. 5, n. 1, p. 90-111, mar./ago. 2014. 
Elaboramos essa ficha documental através da seguinte linha de pensamento: cada item proposto por Kossoy (2001) foi analisado tendo em vista as categorias sugeridas no quadro de Manini (2008). O DE genérico e específico, composto pelos campos QUEM/O QUE, ONDE, QUANDO e COMO, representará de maneira abrangente e detalhada os metadados recomendados com base na bibliografia especializada e nas fichas de catalogação dos museus selecionados. No item Identidade do documento + características individuais, os metadados deveram descrever o objeto/documento no contexto da sua nova história (FERREZ, 1994) dentro da instituição; no item Informações referentes ao assunto, os metadados visam apresentar o conteúdo imagético da fotografia e suas inter-relações com o meio sóciohistórico-cultural; para o item Informações referentes ao fotógrafo, os metadados buscam representar a trajetória e características do autor do objeto/documento; e no item Informações referentes à tecnologia, os metadados devem descrever o contexto tecnológico em que a fotografia faz parte. Com relação às categorias Sobre e Dimensão expressiva, incorporadas em cada item, trataremos na ficha documental como campos generalizados que estimulam a inserção de metadados em uma abordagem abrangente, relacionada aos procedimentos institucionais e questões que envolvem a representação da fotografia como objeto/documento museológico.

\section{Análise dos resultados}

A partir da elaboração da ficha documental (quadro 3), destacamos e refletimos sobre quais informações parecem importantes serem descritas para o pesquisador que investiga a fotografia histórica no contexto do museu. Sendo assim, por meio da análise das fichas de catalogação dos Museus de Imagem e do Som selecionados e da bibliografia especializada, pudemos chegar a um conjunto de metadados que descrevesse de forma genérica e específica elementos que representam a fotografia histórica enquanto objeto museológico que também é fonte de informação científica, conforme preconizado por Loizos (2008).

Para tanto, inserimos os metadados das fichas dos museus considerados importantes para organização da informação da fotografia histórica tendo por foco sua característica quanto documento de pesquisa. Cabe ressaltar que durante o tratamento dos dados, constatamos a necessidade de criar metadados tendo em vista que aspectos da ficha documental não estavam previstos nos metadados das fichas analisadas. Estes foram indicados com base na interpretação da bibliografia especializada.

InCID: R. Ci. Inf. e Doc., Ribeirão Preto, v. 5, n. 1, p. 90-111, mar./ago. 2014. 
O tratamento dos metadados por meio da ficha documental resultou na proposta apresentada a seguir:

Quadro 4: Proposta de metadados para descrição de fotografia histórica

\begin{tabular}{|c|c|c|c|c|c|c|c|}
\hline \multicolumn{2}{|c|}{$\begin{array}{l}\text { 1. Identidade do documento + } \\
\text { características individuais }\end{array}$} & \multicolumn{2}{|c|}{$\begin{array}{l}\text { 2. Informações referentes ao } \\
\text { assunto }\end{array}$} & \multicolumn{2}{|c|}{$\begin{array}{c}\text { 3. Informações referentes ao } \\
\text { fotógrafo }\end{array}$} & \multicolumn{2}{|c|}{$\begin{array}{l}\text { 4. Informações referentes à } \\
\text { tecnologia }\end{array}$} \\
\hline \multicolumn{2}{|c|}{$\overline{D E}$} & \multicolumn{2}{|c|}{ DE } & \multicolumn{2}{|c|}{ DE } & \multicolumn{2}{|c|}{$\overline{D E}$} \\
\hline Genérico & Especifico & Genérico & Especifico & Genérico & Especifico & Genérico & Especifico \\
\hline Quem/O que & Quem/O que & Quem/O que & Quem/O que & Quem/O que & Quem/O que & Quem/O que & Quem/O que \\
\hline $\begin{array}{l}\text { Título/No de } \\
\text { registro }\end{array}$ & $\begin{array}{l}\text { Registrado } \\
\text { por/Outros } \\
\text { números }\end{array}$ & Descritores & $\begin{array}{l}\text { Descritores } \\
\text { onomásticos }\end{array}$ & Autor & Estúdio & $\begin{array}{l}\text { Equipamento } \\
\text { utilizado }\end{array}$ & Suporte físico \\
\hline Onde & Onde & Onde & Onde & Onde & Onde & Onde & Onde \\
\hline Localização & $\begin{array}{l}\text { Posição no } \\
\text { álbum/série }\end{array}$ & Local & $\begin{array}{l}\text { Descritores } \\
\text { geográficos }\end{array}$ & $\begin{array}{l}\text { Local de } \\
\text { nascimento }\end{array}$ & $\begin{array}{l}\text { Local de } \\
\text { atuação }\end{array}$ & $\begin{array}{l}\text { Fabricação do } \\
\text { equipamento }\end{array}$ & $\begin{array}{l}\begin{array}{l}\text { Fabricação do } \\
\text { suporte }\end{array} \\
\end{array}$ \\
\hline Quando & Quando & Quando & Quando & Quando & Quando & Quando & Quando \\
\hline $\begin{array}{l}\text { Data de } \\
\text { aquisição }\end{array}$ & Data de registro & Data & $\begin{array}{l}\text { Data das } \\
\text { anotações }\end{array}$ & $\begin{array}{l}\text { Período de } \\
\text { trabalho do } \\
\text { fotógrafo }\end{array}$ & $\begin{array}{l}\text { Data de } \\
\text { impressão }\end{array}$ & $\begin{array}{l}\text { Período do } \\
\text { equipamento }\end{array}$ & $\begin{array}{l}\text { Período do } \\
\text { suporte físico }\end{array}$ \\
\hline Como & Como & Como & Como & Como & Como & Como & Como \\
\hline Procedência & $\begin{array}{l}\text { Modo de } \\
\text { aquisiçãão }\end{array}$ & Anotações & Transcrição & $\begin{array}{l}\text { Característica } \\
\text { de estilo }\end{array}$ & $\begin{array}{l}\text { Ambiente } \\
\text { fotografado }\end{array}$ & $\begin{array}{l}\text { Processo } \\
\text { fotográfico }\end{array}$ & $\begin{array}{l}\text { Natureza do } \\
\text { original }\end{array}$ \\
\hline \multicolumn{2}{|l|}{ Sobre } & \multicolumn{2}{|l|}{ Sobre } & \multicolumn{2}{|l|}{ Sobre } & \multicolumn{2}{|l|}{ Sobre } \\
\hline \multicolumn{2}{|c|}{$\begin{array}{l}\text { Estado de conservação } \\
\text { Ex-proprietário } \\
\text { Observações }\end{array}$} & \multicolumn{2}{|c|}{$\begin{array}{l}\text { Histórico } \\
\text { Elementos simbólicos } \\
\text { Observações }\end{array}$} & \multicolumn{2}{|l|}{ Observações } & \multicolumn{2}{|c|}{\begin{tabular}{|l} 
Formato \\
Cromia \\
Dimensão Física \\
Descrição Física \\
Gênero \\
Observações \\
\end{tabular}} \\
\hline \multicolumn{2}{|c|}{ Dimensão expressiva } & \multicolumn{2}{|c|}{ Dimensão expressiva } & \multicolumn{2}{|c|}{ Dimensão expressiva } & \multicolumn{2}{|c|}{ Dimensão expressiva } \\
\hline \multicolumn{2}{|l|}{$\begin{array}{l}\text { Exposições } \\
\text { Publicações } \\
\text { Intervenções } \\
\text { Autorização de }\end{array}$} & \multicolumn{2}{|c|}{ Referência bibliográfica } & \multicolumn{2}{|c|}{ Objetos associados } & \multicolumn{2}{|l|}{ Técnica } \\
\hline
\end{tabular}

Fonte: criado pela autora, 2013.

A análise está estruturada por cada tópico da ficha documental, 1. Identidade do documento + características individuais, 2. Informações referentes ao assunto, 3. Informações referentes ao fotografo e 4. Informações referentes à tecnologia. Sendo assim, foram traçadas considerações com relação à importância de cada metadado estabelecido para a descrição de fotografia histórica, com base em cada tópico apresentado acima, de modo a atender, principalmente, as necessidades informacionais do pesquisador deste objeto/documento. 


\section{Identidade do documento + características individuais}

Esse primeiro tópico visa à identificação e o reconhecimento do objeto pela instituição museológica, ou seja, é o primeiro passo no tratamento documental do objeto ao ser musealizado segundo expõe Kossoy (2001). Consideramos a importância deste para a descrição, uma vez que legitima a fotografia histórica como objeto de valor patrimonial, pois passa efetivamente a ser adquirido e preservado no museu, como também o caracteriza como fonte de pesquisa científica no momento em que determina pontos de acesso a ela.

Passamos a compreensão de cada categoria estabelecida na proposta (quadro 4) referente a esse tópico. No que tange QUEM/O QUE, genérico e específico, incluímos os metadados referentes ao título e o $\mathbf{n}^{\mathbf{0}}$ de registro que, conforme verificamos em Ferrez (1994), sua importância é indiscutível, tendo em vista serem dados que permitem o reconhecimento do objeto na instituição. Ainda com relação a essa categoria, acreditamos que o metadado registrado por é extremamente importante para o museu, uma vez que, de acordo com Smit (2011), a documentação de gestão do acervo museológico e administrativo permite a segurança do objeto e o controle institucional. É este metadado que registra a responsabilidade daquele que inclui os dados descritivos, por exemplo, em caso de dúvidas o pesquisador saberá a quem recorrer. Quanto ao metadado outros números, identificamos que esse é igualmente necessário, pois pode haver casos do objeto ter pertencido à outra instituição, bem como o museu ter passado por uma renumeração do seu acervo e para tanto os números anteriormente registrados devem continuar pertencendo à história do objeto. Trata-se das perdas sugeridas por Ferrez (1994), segundo já mencionadas no referencial teórico desta pesquisa.

No campo de aferição ONDE, genérico e específico, incluímos a localização do objeto na instituição e a posição que se encontra dentro do conjunto ao qual faz parte. Evidenciamos a importância da incorporação dos metadados localização e posição na ficha de catalogação de acervo fotográfico histórico, tendo em vista que estes campos facilitam a recuperação física do objeto de forma fácil e eficiente. Pois, quanto mais específico o detalhamento da descrição do objeto no acervo, que pode compor um álbum, uma série ou um setor (KOSSOY, 2001), maior será a facilidade de sua recuperação pelo pesquisador, bem como poderá auxiliar na identificação das possíveis relações do objeto, dentro de um conjunto ou individualmente.

InCID: R. Ci. Inf. e Doc., Ribeirão Preto, v. 5, n. 1, p. 90-111, mar./ago. 2014. 
O item QUANDO, genérico e específico, trata das datas, referente à aquisição do objeto e de registro da instituição. São metadados que orientam os dois públicos, denominados por Smit (2011), funcionário e público em geral. No caso desta pesquisa, o público geral refere-se ao pesquisador. No que diz respeito ao COMO, genérico e específico, selecionamos o metadado procedência, o qual Ferrez (1994) aponta como primordial para reconhecer a origem do objeto e o modo de aquisiçãa que, de acordo com Moro (1986), corresponde ao processo fundamental de maior responsabilidade do museu para com o objeto. Estes também contribuem para o registro administrativo e de gestão de acervos, ações muito relevantes ressaltadas no estudo de Smit (2011).

No item SOBRE, encontraremos metadados como: estado de conservação e exproprietário. $O$ primeiro trata do diagnóstico referente às circunstâncias em que se encontra o objeto (KOSSOY, 2001) e o segundo visa reconhecer o antigo dono do objeto. Por exemplo, em caso de doação ou compra cabe nesse campo especificar quem é o ex-proprietário do objeto, como sugere a ficha de catalogação do museu inserido na base Joconde (MINISTÈRE DE LA CULTURE ET DE LA COMMUNICATION, 2013), cuja denominação é “Anciennes appartenance".

Para DIMENSÃO EXPRESSIVA, destacamos os metadados relacionados com os ganhos e as perdas do objeto no acervo, sugeridos por Ferrez (1994). É nesse item que deve ser relatada a trajetória do objeto na instituição. Identificar as ações pelas quais a fotografia histórica passa enquanto objeto de museu, como as exposições, publicações e restauro dará maior consistência às informações referente a ele, bem como questões relacionadas com o uso e acesso já que estamos lidando com o pesquisador e suas necessidades.

Sendo assim, incluímos na DIMENSÃO EXPRESSIVA os metadados exposições, publicações, intervenções e autorização de uso. O termo "exposições" foi retirado da ficha do museu que está na base de dados MatrizNet - Portugal (MINISTÉRIO DA CULTURA DE PORTUGAL, 2013) e que Ferrez (1994) alerta como uma ação na qual o objeto museológico, muitas vezes, passa e por isso deve ser evidenciada para relatar a história do mesmo dentro na instituição. Com relação aos termos "bibliografia" e "multimídia", que também constam na ficha da base de dados de Portugal, observamos que são metadados empregados para inserir referências de publicações com a imagem fotográfica em diferentes suportes. Dessa forma, ao compreendermos que estamos tratando de fotografias históricas, que são fontes de informação científica, a publicação destas em diversos meios se torna algo essencial e constante. Por isso, 
identificamos como metadados importantes, porém optamos por usar o termo publicações para compor essas representações independentemente do suporte que foi publicado. $\mathrm{O}$ metadado intervenções faz menção às interferências de restauro no objeto, pois, conforme expõe Ferrez (1994), o objeto perde informação quando é restaurado por isso é necessário registrar essas etapas que o mesmo passa na instituição. Com relação ao metadado autorização de uso, verificamos a importância de se documentar as possibilidades de uso e acesso destas imagens fotográficas, como podemos averiguar na ficha de catalogação do museu da base Joconde (MINISTÈRE DE LA CULTURE ET DE LA COMMUNICATION, 2013) cujo metadado é denominado de "Copyright notice”.

\section{Informações referentes ao assunto}

Esse tópico preocupa-se com as informações contidas na imagem fotográfica, ou seja, por meio dele podemos compreender o assunto representado e identificar múltiplas possibilidades de interpretações. Verificamos que esta etapa, para a descrição de fotografia histórica, é fundamental para compor as conexões históricas, culturais, sociais, artísticas e econômicas, que este objeto/documento possui e que, para tanto, faz dele um bem cultural que deve ser preservado. Além disso, consideramos que as informações referentes ao assunto representado na fotografia histórica são, muitas vezes, o ponto de partida para pensar meios de exposição e publicação deste objeto/documento.

Dessa forma, passamos a análise de cada metadado estabelecido na proposta (quadro 4) referente a esse tópico. No que diz respeito à categoria QUEM/O QUE, genérico e específico, destacamos os metadados descritores e descritores onomásticos, que tratam dos itens que descrevem o conteúdo representado na imagem, os quais Kossoy (2001) ressalta como de extrema relevância. O primeiro metadado faz referência a um conjunto mais amplo de conceitos que compõem o assunto representado na imagem fotográfica e, o segundo, específica possíveis personalidades ou instituições e/ou organizações que possam conter na imagem. Identificar esses componentes, muitas vezes, é o que confere valor para a fotografia por possuir instituições e/ou pessoas ilustres que compõem a cena exposta.

Com relação ao ONDE, genérico e específico, consideramos a importância de se destacar o local no qual foi tirada a fotografia. Sobre a utilidade deste item de descrição, Ferrez (1994) argumenta sua importância quando afirma que por meio deste podemos 
reconhecer a localidade na qual a cena faz parte. Outro metadado considerado por nós são os descritores geográficos, cuja função é destacar referências internacionais, nacionais, regionais ou locais presentes na imagem, o que também permite ao pesquisador uma melhor visualização do lugar em que a imagem foi registrada. Podemos confirmar a relevância deste metadado quando verificamos a sua presença, com a denominação "Geografic subject", na base de dados do Museu Getty (GETTY RESEARCH INSTITUTE DIGITAL, 2013).

No campo de aferição QUANDO, genérico e específico, constatamos a necessidade de metadados que façam menção a data da imagem fotográfica e a data das anotações. Esses metadados permitem que o pesquisador identifique o período em que a imagem foi capturada; assim como, por meio da data das possíveis inscrições, podemos contextualizar questões sociais, históricas, culturais, artísticas e econômicas (KOSSOY, 2001) contidas na fotografia.

Para a categoria COMO, genérico e específico, anotações é um metadado referente a marcas e assinaturas na fotografia e transcrições é a reprodução dessas. Segundo Bottallo (2010), no que se refere às transcrições, essas devem respeitar a grafia original e o idioma de quaisquer inscrições inseridas no objeto. Estes metadados permitem que o pesquisador possa obter algumas respostas para seus possíveis questionamentos. Entendemos que esses metadados contextualizam o objeto, as "assinaturas", por exemplo, para identificar o fotógrafo, ou "legendas" para identificar o proprietário da fotografia ou o motivo da capturação da mesma, seja presenteando alguém, indicando quem aparece na imagem ou uma dedicatória. São formas que contribuem para a análise do pesquisador. Além do mais, "marcas" de estúdios aproximam o pesquisador com relação à origem e fabricação do objeto. É fundamental que os profissionais da informação, que trabalham nos museus, não deixem nenhuma dessas informações de fora. Por isso, deverão ser transcritas para preservar a veracidade da informação.

No que tange o SOBRE, evidenciamos o metadado histórico da fotografia que procura contextualizar e compreender as relações extrínsecas que a envolvem e o metadado elementos simbólicos que compõe as interpretações simbólicas de cunho social e cultural representadas na imagem fotográfica (KOSSOY, 2001). Quanto a DIMENSÃO EXPRESSIVA, esta diz respeito às referências bibliográficas sugestão tanto de SMIT (2011) como de FERREZ (1994) que tratam sobre as bases teóricas que possuem relação com o assunto do objeto fotográfico.

InCID: R. Ci. Inf. e Doc., Ribeirão Preto, v. 5, n. 1, p. 90-111, mar./ago. 2014. 


\section{Informações referentes ao fotógrafo}

O presente tópico busca identificar o fotógrafo e/ou estabelecimento, autor do registro, enquadrando-o num cenário social diante das relações que o envolvem. Este tópico traça a identidade pessoal e profissional do autor, destacando características referentes à sua dinâmica de atuação no campo da fotografia, bem como seu comportamento individual e social (KOSSOY, 2001). Ressaltamos a importância deste item para descrição de fotografia histórica, uma vez que se reconhece no autor da fotografia a essência do processo de criação desta e, que, para tal, necessita ser apreciado.

Diante disso, apresentamos a inclusão dos metadados correspondente a cada categoria estabelecida na proposta (quadro 4). Ao tratarmos do QUEM/O QUE, genérico e específico, destacamos o metadado autor que visa identificar o fotógrafo que captura a imagem; já o metadado estúdio objetiva dar créditos as outras possibilidades de autoria que possam surgir. Arriscamos dizer que estes metadados se referem às autorias pessoal e institucional tratadas pela catalogação na área da Ciência da Informação. A título de exemplo, observamos que este metadado está presente, com a denominação "oficina/fabricante", na ficha de catalogação do catálogo coletivo on-line MatrizNet - Portugal (MINISTÉRIO DA CULTURA DE PORTUGAL, 2013). A presença deste metadado no catálogo português passa a ser considerado como um reforço a nossa escolha.

Com relação à categoria ONDE, genérico e específico, identificamos os metadados local de nascimento e local de atuação, ambos visando extrair maiores informações sobre o fotógrafo. Quanto mais apontarmos informações sobre este, mais descobriremos sobre a imagem representada, e assim, melhor a descreveremos. Para tanto, no campo QUANDO, genérico e específico, estipulamos metadados que tratam do período de trabalho do fotógrafo e a data de impressão da fotografia, cujo intuito é saber mais sobre a vida profissional do fotógrafo, bem como do objeto/documento.

No que tange o COMO, genérico e específico, destacamos os metadados referentes às características de estilo do fotógrafo, cujas evidencias comprovam seu modo de fotografar, ou seja, de acordo com Kossoy (2001) esse campo compõem as peculiaridades na tomada de registro. Já o metadado específico diz respeito ao ambiente fotografado. A intenção é perceber que tipo de locais o fotógrafo costumava fotografar, por exemplo, se em locais fechados ou abertos. Para o SOBRE, indicamos o metadado observações para tratar de todas 
as informações encontradas sobre o fotógrafo que não possui metadado equivalente na ficha documental. Quanto a DIMENSÃO EXPRESSIVA, sugerimos o metadado objetos associados que faz alusão a outros objetos que podem estar no acervo do museu e que possuem relação com o fotógrafo e/ou estúdio, por exemplo, uma câmera fotográfica utilizada por ele. Esse metadado deve ser relacionado com objetos que fazem menção ao fotógrafo ou ao estúdio, pois em se tratando de acervos museológicos, compreendemos que sua unidade existe dentro de uma diversidade, ou seja, suas coleções são formadas por um conjunto maior de objetos variados.

\section{Informações referentes à tecnologia}

O referido tópico visa identificar as informações sobre os processos e técnicas utilizados na elaboração da fotografia, no que diz respeito às particularidades de acabamento e características físicas do objeto. Segundo Kossoy (2001, p.25), "Seu consumo crescente e ininterrupto ensejou o gradativo aperfeiçoamento da técnica fotográfica.". Nesse contexto, tendo em vista que a fotografia sofreu incontáveis modificações tecnológicas ao longo de sua trajetória, desde sua criação até o presente, esse tópico busca traçar um reconhecimento sobre essas transformações.

Ao incorporarmos os metadados apropriados a cada categoria estabelecida na proposta (quadro 4), iniciaremos uma reflexão sobre as partes que compõem esse tópico. Em relação ao QUEM/O QUE, genérico e específico, verificamos a necessidade da inserção dos metadados equipamento e suporte físico, uma vez que o primeiro permite identificarmos o aparelho (FLUSSER, 2011), parte importante para a compreensão das relações sociais que envolvem o objeto, já o segundo trata do tipo de suporte físico em que a imagem fotográfica foi exposta. Conforme Manini (2010) são muitos os sustentáculos de uma fotográfica história, por exemplo, os negativos de vidro. Mais uma vez recorremos a ficha de catalogação apresentada na base MatrizNet - Portugal (MINISTÉRIO DA CULTURA DE PORTUGAL, 2013) em que o metadado "suporte" é um item a ser descrito. Além disso, verificamos que este metadado é o único que está presente em todas as fichas dos museus analisados e que possui a mesma nomenclatura, ou seja, trata-se de um campo de registro determinante para os museus no momento de descrever a fotografia histórica, uma vez que essa pode ser fixada em variados tipos de materiais, segundo expõe Manini (2008).

InCID: R. Ci. Inf. e Doc., Ribeirão Preto, v. 5, n. 1, p. 90-111, mar./ago. 2014. 
No ONDE, genérico e específico, incluímos a fabricação do equipamento e fabricação do suporte, tendo em vista a existência de históricas fábricas que por muito tempo dominaram o mercado fotográfico conforme explícita Kubrusly (2006), por exemplo, a $\mathrm{KODAK}^{4}$. Para o campo de aferição QUANDO, genérico e específico, indicamos os metadados período do equipamento e período do suporte físico, ambos são necessários tendo em vista que a tecnologia avançou aceleradamente e com ela as transformações dos aparelhos e suportes. Dados que, a nosso ver, são muito relevantes porque permitem que o pesquisador se oriente no tempo-espaço da ocorrência do ato fotográfico. No que se refere ao COMO, genérico e específico, registramos os metadados processo fotográfico e natureza do original. Segundo Manini (2010), informar sobre o processo fotográfico é importante porque permite que identifiquemos a trajetória da fotografia, em diferentes épocas, por meio dos diferentes processos químicos pelos quais passaram. A natureza do original, conforme Kossoy (2001) tem utilidade para o pesquisador devido ao fato de possibilitar que ele reconheça se a fotografia histórica se trata de um negativo, de um positivo ou de uma cópia. Essa informação pode tornar o objeto/documento mais ou menos raro.

$\mathrm{Na}$ categoria SOBRE, verificamos os metadados: formato, descrição física, dimensão física e cromia. Estes são características intrínsecas ao objeto, fazem referência aos elementos descritivos que compõem a sua estrutura física. Registramos também nesta categoria o metadado gênero que está relacionado ao tipo de fotografia, por exemplo, a paisagem. Estes metadados foram encontrados na ficha da base de dados do Museu Getty (GETTY RESEARCH INSTITUTE DIGITAL, 2013), bem como foram citados como importantes por vários autores estudados (MANINI, 2008 e 2010; KOSSOY, 2001; BOTTALlO, 2010; PAVÃO, 1997) entre outros. Para a DIMENSÃO EXPRESSIVA, recomendamos a utilização do metadado técnica, tendo em vista sua ocorrência em duas fichas de catalogação: base do Museu Getty (GETTY RESEARCH INSTITUTE DIGITAL, 2013) e do MatrizNet - Portugal (MINISTÉRIO DA CULTURA DE PORTUGAL, 2013), assim como nas indicações de Manini (2008; 2010) que sugere a descrição da técnica fotográfica como um dado importante a ser considerado devido suas múltiplas possibilidades.

Com relação ao metadado observações, destacamos que este foi incorporado em todas as quatro categorias da proposta (quadro 4), tendo em vista ter este item à função de

\footnotetext{
${ }^{4}$ Fundado por George Eastman, inventor do filme fotográfico em 1888, a KODAK nasceu em 1892 como uma empresa multinacional dedicada a produção e comercialização de equipamentos fotográficos profissionais e amadores, como também para a área da saúde.
} 
complementar outros dados registrados na proposta e, assim, tornar a descrição mais completa. Por mais que a nomenclatura seja a mesma, cada um foi considerado como um campo por estar sendo aplicado a contextos distintos de descrição.

\section{Considerações finais}

Este artigo buscou apresentar que o museu é um espaço, entre tantas funções, destinado à pesquisa e que para tanto deve organizar seu acervo de modo a atender as necessidades informacionais do pesquisador especializado que investiga o objeto museológico como fonte de informação. Evidenciamos a fotografia histórica como um objeto/documento, fonte de pesquisa científica, que se encontra salvaguardada em muitos museus brasileiros e que possui diversas características informacionais intrínsecas e extrínsecas a ela que devem ser descritas.

A proposta para descrição de fotografias históricas salvaguardadas em acervos museológicos totalizou um conjunto de 54 metadados visando atender as necessidades informacionais do pesquisador. Cabe ressaltar, que ocorreu a necessidade de criarmos 18 metadados para a adequação na proposta de descrição de fotografia histórica. São esses: elementos simbólicos, data das anotações, local de nascimento, período de trabalho do fotógrafo, estúdio, local de atuação, características de estilo, ambiente fotografado, equipamento utilizado, fabricação do equipamento, período do equipamento, fabricação do suporte, período do suporte físico, natureza do original, ex-proprietário, exposições, publicações, intervenções. Nossa proposta de conjunto de metadados se apresenta como uma sugestão para que as instituições repensem suas formas de descrever a fotografia histórica salvaguarda em museus, pensando em facilitar o acesso e a recuperação da informação pelos pesquisadores que busca no acervo da instituição sua fonte de informação.

Os outros 36 metadados restantes na proposta foram retirados das fichas de catalogação dos museus analisados, mas devemos levar em consideração o fato de que nem todos estavam presentes nas quatro fichas analisadas. Constatamos que: onze estavam em todas as fichas; nove em três das fichas; quatro em apenas duas fichas e doze encontradas em apenas uma ficha. Podemos perceber com isso, que não há ainda uma preocupação visível de interoperabilidade institucional, mesmo quando estamos tratando de museus de mesma tipologia, o que nos permite questionar o quanto os museus estão preocupados em serem espaços de pesquisa, como sugere a Lei no 11.409/2009.

InCID: R. Ci. Inf. e Doc., Ribeirão Preto, v. 5, n. 1, p. 90-111, mar./ago. 2014. 
Pretendemos com a criação da proposta de descrição de acervos fotográficos históricos contribuir e instigar os museus a ocuparem cada vez mais seu papel como entidades de pesquisa, por meio da organização do seu acervo e da valorização dos objetos enquanto fonte de informação. Acreditamos que o papel social do museu é, também, dar acesso às informações contidas nos acervos salvaguardados, de modo que faça circular a informação e crie condições para que a comunicação entre museu e público seja renovada, permitindo a troca de conhecimento.

\section{Referências}

BARBUY, H. Documentação museológica e pesquisa em museus. In: MUSEU DE ASTRONOMIA E CIÊNCIAS AFINS (MAST). Documentação em Museus, v.10. Rio de Janeiro: MAST, 2008. Anais... Rio de Janeiro: MAST Colloquia; 2008. p. 33- 45.

BOTTALLO, M. Diretrizes em documentação museológica. In: ASSOCIAÇÃO CULTURAL DE AMIGOS DO MUSEU CASA DE PORTINARI. Documentação e conservação de acervos museológicos: diretrizes. Brodowski: Associação Cultural de Amigos do Museu Casa De Portinari; São Paulo: Secretaria de Estado da Cultura de São Paulo, 2010, p. 48-79.

BRASCHER, M.;CAFÉ, L. Organização da informação ou organização do conhecimento. In: ENCONTRO NACIONAL DE PESQUISA EM CIÊNCIA DA INFORMAÇÃO ENANCIB, São Paulo, 2008. Anais..., São Paulo: Encontro Nacional de Pesquisa em Ciência da Informação; 2008. p. 1-14.

BRASIL. Lei ${ }^{\circ} 11.904$, de 14 de janeiro de 2009. Institui o Estatuto de Museus e dá outras providências. Diário Oficial [da] República Federativa do Brasil, Brasília, DF, 15 jan. 2009. Disponível em: < http://www.planalto.gov.br/ccivil_03/_Ato2007-

2010/2009/Lei/L11904.htm>. Acesso em: 28 nov. 2013.

CAFÉ, L.; SALES, R. Organização da Informação: conceitos básicos e breve fundamentação teórica. In: ROBREDO, J.; BRÄSCHER, M. (Org.). Passeios pelo bosque da informação: estudos sobre a representação e organização da informação e do conhecimento. Brasília: IBICT, 2010, p. 115- 119.

CAMPOS, M. L. C; CAMPOS, M. L. A.; CAMPOS, L. M. Web semântica e a gestão de conteúdos informacionais. In. MARCONDES, C. H. et al. Bibliotecas digitais: saberes e práticas. Salvador, Brasília: UFBA, IBICT, 2006. p. 55-73.

CINTRA, A. M. M. et al. Para entender as linguagens documentarias. 2. ed. São Paulo: Polis, 2002. 92 p. (Coleção Palavra-chave).

CUNHA, I. M. R. F. Análise documentária. In: SMIT, J. W (Coord.). Analise documentária: a análise da síntese. Brasília: Instituto Brasileiro de Informação em Ciência e Tecnologia, 1987, p. 39- 62. 
FERREZ, H. D. Documentação museológica: teoria para uma boa prática. Cadernos de ensaios, Rio de Janeiro, n. 2 - Estudos de museologia, p. 64-73, 1994.

FLUSSER, V. Filosofia da caixa preta: ensaios para uma futura filosofia da fotografia. São Paulo: Annablume, 2011.

GETTY RESEARCH INSTITUTE DIGITAL. 2013. Disponível em: < https://www.getty.edu/research/tools/digital_collections/>. Acesso em: 17 set. 2013

KEBRUSLY, C. A. O que é fotografia. 4 ed. São Paulo: Brasiliense, 2006, 131 p.

KOSSOY, B. Fotografia e história. 2. ed. São Paulo: Ateliê, 2001.

LEITE, M. M. Retratos de família: leitura da fotografia histórica. 3. ed. São Paulo: EdUSP, 2001.

LOIZOS, P. Vídeo, filme e fotografias como documentos de pesquisa. In: BAUER, M. W.; GASKELL, G. (Ed.). Pesquisa qualitativa com texto: imagem e som: um manual prático. 7. ed., Petrópolis: Vozes, 2008, p. 137- 155.

LOUREIRO, J. M. M. Esboço acerca da documentação museológica. In: MUSEU DE ASTRONOMIA E CIÊNCIAS AFINS (MAST). Documentação em Museus, v. 10. Rio de Janeiro: MAST, 2008. Anais... Rio de Janeiro: MAST Colloquia, 2008. p. 23- 33.

MANINI, M. P. A fotografia como registro e como documento de arquivo. In: BARTALO, L.; MORENO, N. A. (Org.). Gestão em arquivologia: abordagens múltiplas. Londrina: EDUEL, 2008. p. 119-183.

MANINI, M. P. Leitura de informações imagéticas: ajustes ainda necessários ao "novo" paradigma. In: ; MARQUES, O. G.; MUNIZ, N. C. (Org.) Imagem, memória e informação. Brasília: Ícone, 2010. p. 11-31.

MARCONDES, C. H. Metadados: descrição e recuperação de informações na Web. In: . et al. (Org.). Bibliotecas digitais: saberes e práticas. 2. ed. Salvador; Brasília: EDUFBA; IBICT, 2006, p. 95-111.

MINISTÈRE DE LA CULTURE ET DE LA COMMUNICATION. JOCONDE: Portail des collections des musées de France. 2013. Disponível em: < http://www.culture.gouv.fr/documentation/joconde/fr/pres.htm>.Acesso em: 17 set. 2013.

MINISTÉRIO DA CULTURA DE PORTUGAL. MatrizNet. 2013. Disponível em: $<$ http://www.matriznet.dgpc.pt/MatrizNet/Objectos/ObjectosConsultar.aspx?IdReg=854>. Acesso em: 17 set. 2013.

MORO, F. C. Museu: Aquisição e documentação. Rio de Janeiro: Livraria Eça, 1986.

ORTEGA, C. D. Fundamentos da organização da informação frente à produção de documentos. Tansinformação, Campinas, v. 20, n. 1, p. 7-15, jan./abr., 2008. Disponível em: $<$ http://periodicos.puc-campinas.edu.br/seer/index.php/transinfo/article/view/537>. Acesso em: 14 ago. 2012 
PAVÃO, L. Conservacção de colecções de fotografia. Lisboa: Dinalivro, 1997.

ROUILLÉ, A. A fotografia: entre documento e arte contemporânea. São Paulo: Senac, 2009.

SMIT, J. W. A representação da imagem. Informare, Rio de Janeiro, v. 2, n. 2, p. 28- 36, jul. /dez. 1996.

Propostas para a indexação de informação iconográfica, 1997. (Mimeo).

A interoperabilidade semântica entre os diferentes sistemas de informação no museu. In: BEVILACQUA, G. M. F.; MARINGELLI; I. C. A. S. (Coord.). I Seminário serviços de informação em museus. São Paulo: Pinacoteca do Estado, 2011, p. 33-41.

SOFKA, V. A pesquisa no museu e sobre o museu. Revista eletrônica do Programa de PósGraduação em Museologia e Patrimônio PPG-PMUS Unirio/ MAST, Rio de Janeiro, v. 2, n. 1, p. 79-84, 2009. Disponível em:

$<$ http://revistamuseologiaepatrimonio.mast.br/index.php/ppgpmus/article/view/49>. Acessado em: 15 mar. 2013.

Artigo submetido em: 03 fev. 2014

Artigo aceito em: 19 mar. 2014 